\title{
Use of aspirin, so variable in its cardiovascular efficacy, should be monitored to assure platelet function is adequately inhibited.
}

\author{
Bruce Rothschild ${ }^{1}$ \\ ${ }^{1} \mathrm{IU}$ Health
}

June 10, 2020

The article by Veronese et al. ${ }^{1}$ on aspirin utilization illustrates a common issue in medicine, validating efficacy and safety of therapeutics and the balance sought. Among the many, often predictable factors affecting clinical efficacy, is the mechanism of action, the physiologic/pharmacologic properties that produce the desired result. For aspirin, the major clinically pertinent effect is reduction of platelet aggregation/stickiness. It was once believed that low dose aspirin was sufficient for this benefit and it was assumed that treatment failures were related to other factors. ${ }^{2}$ However, medicine has moved into the era of evidence-based assessments. And, when efficacy of aspirin in reducing platelet aggregation was actually tested in vitro, routine prescription of aspirin was found to be variable in such reduction. Ten times the 81 mg dose was often required to alter results in the appropriate collagen and ADP platelet function tests. ${ }^{3}$ Further complicating assessment of aspirin efficacy are individuals with anti-phospholipid syndrome. Anti-phospholipid antibodies are not rare. ${ }^{4}$ Afflicted individuals require warfarin-induced prothrombin time INRs in excess of standard dosing $^{5}$ and the very convenient fractionated heparins lack efficacy in preventing thromboembolic events. ${ }^{6}$ Similar potential issues perhaps deserve consideration in establishing and applying aspirin recommendations. Recognizing that aspirin use carries with it morbidity and even mortality risks, ${ }^{7}$ should not its efficacy (at the prescribed dose) be routinely subject to in vitro (platelet function) testing? If we are to prescribe a medication for a specific benefit, it seems only reasonable to verify that individual variation does not interfere with the desired mechanism of action? The issue is not whether to use aspirin but, rather, how. Risk without assuring potential benefit should be avoided. Are the individuals who bleed more likely to be those for whom dosage was suboptimal? Perhaps we should assure adequate dose or not use it at all.

B Rothschild, 5010 N Weir, Muncie, IN 47303, 785-615-1523, spondylair@gmail.com

There are no financial associations or other possible conflicts .

1. Veronese N, Demurtas J, Thompson T, et al. Effect of low-dose aspirin on health outcomes: An umbrella review of systemic reviews andmeta-analyses. Br J Clini pHarmacol 2020;1-11. Doi: $10.1111 /$ bcp. 14310

2. Arnaud L, Mathian A, Ruffatti A, et al. Efficacy of aspirin for the primary prevention of thrombosis in patients with antiphospholipid antibodies: An international and collaborative metaanalysis.Autoimmun Rev 2014;13:281-291.

3. Perneby C, Wallén NH, Rooney C, et al. Dose- and time-dependent antiplatelet effects of aspirin. Thromb Haemost 2006;95:652-658

4. Garcia D, Erkan D. Diagnosis and management of the antiphospholipid syndrome. N Eng J Med. 2018;378:2010-2021.

5. Khamashta MA, Cuadrado MJ, Mujic F, et al. The management of thrombosis in the antiphospholipidantibody syndrome. N Engl J Med 1995;332:993-997.

6. Ziakas PD, Pavlou M, Voulgarelis M. Heparin treatment in antiphospholipid syndrome with recurrent pregnancy loss: A systematic review and meta-analysis. Obstet Gynecol 2010;115:1256-1262 
7. Gaziano M, Brotons C, Coppolecchia R, et al. Use of aspirin to reduce risk of initial vascular events in patients at moderate risk of cardiovascular disease (ARRIVE): A randomized, double-blind, placebocontrolled trial. Lancet 2018;392:1036-1046. 